\title{
Comisión de Investigación y Acusación de la Cámara de Representantes: una fractura al sistema de responsabilidad de altos jueces en Colombia ${ }^{\star}$
}

\author{
The House of Representatives Committee of Prosecution and Inquiry: \\ a Breakup into the Responsibility System of Judges in Colombia \\ Comissão de Pesquisa e Acusação da Câmara de Representantes: \\ uma fratura ao sistema de responsabilidade de altos juízes na Colômbia
}

\section{Carolina Guevara *}

FECHA DE RECEPCIÓN: 10 DE DICIEMBRE DE 2014. FECHA DE ACEPTACIÓN: 17 DE ABRIL DE 2015

Doi: dx.doi.org/10.12804/esj 17.02.2015.03

Para citar este artículo: Guevara, C., (2015). Comisión de Investigación y Acusación de la Cámara de Representantes: una fractura al sistema de responsabilidad de altos jueces en Colombia. Estudios Socio-Jurídicos, 17(2), 45-78. Doi: dx.doi. org/10.12804/esj17.02.2015.03

\section{RESUMEN}

En Colombia se asiste a la explosión del número de denuncias por faltas de todo tipo en contra de magistrados de la Corte Suprema de Justicia y del Consejo Superior de la Judicatura. También, se acrecienta la sensación de que los jueces cuentan con suficientes arreglos que garantizan su independencia, sin que a la par se asegure que estos respondan por sus acciones y omisiones. El presente documento busca mostrar cómo pese a la existencia de un cuerpo normativo que busca asegurar que los altos jueces rindan cuentas, en la práctica estos mecanismos se muestran poco eficaces. La fractura al sistema de rendición de cuentas puede rastrearse en la deficiente gestión del ente que por ley controla a los togados: la Comisión de Investigación y Acusación de la Cámara de Representantes.

Palabras clave: Independencia, responsabilidad, accountability, Corte Suprema de Justicia, Consejo Superior de la Judicatura.

* Este artículo es producto del proyecto de investigación de la tesis doctoral titulada Recrutement, indépendance et responsabilité des magistrats en Colombie. Le cas de la Cour Suprême de Justice et du Conseil Supérieur de la Judicature, que se realiza en la Universidad Pierre Mendès-France. Grenoble 2.En general, este proyecto de investigación aborda dos grandes temas, el de la independencia y el de la responsabilidad de los altos jueces en Colombia.

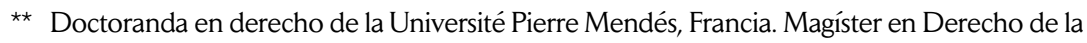
Universidad Nacional de Colombia. Abogada egresada de la Universidad Libre. Correo electrónico: cguevara42@gmail.com 


\section{ABSTRACT}

In these days, we can constant a growing number of offence denunciations against the judges composing the Supreme Court and the ones composing the Supreme Judicial Council. People also feel judges dispose of number of arrangements to guarantee their independence. As a result, there is the feeling judges don't respond for their actions and omissions. This paper intends to show that even if normative rules exist to control judges the control mechanisms don't work. The problem of the control system resides in the poor management of the commission of investigation and prosecution of the House of Representatives, entity that is meant ruling the mentioned control system.

Key words: Independence, responsibility, accountability, Supreme Court, Supreme Judicial Council.

\section{RESUMO}

Na Colômbia assiste-se à explosão do número de denúncias por faltas de todo tipo contra magistrados da Corte Suprema de Justiça e do Conselho Superior da Judicatura. Também, acrescenta-se a sensação de que os juízes contam com suficientes arranjos que garantem sua independência sem que isso assegure que estes respondam pelas suas ações e omissões. $O$ presente documento busca mostrar como embora a existência de um corpo normativo que busca assegurar que os altos juízes prestar conta de suas ações, na prática estes mecanismos mostram-se pouco eficazes. A fratura ao sistema de rendição de contas pode rastear-se (entre outros fatores) na deficiente gestão do ente que por lei controla aos togados: a Comissão de Pesquisa e Acusação da Câmara de Representantes.

Palavras-chave: Independência, responsabilidade, accountability, Corte Suprema de Justiça, Conselho Superior da Judicatura. 
El reverso de la independencia de los jueces es su responsabilidad. Si bien se asume que los jueces deben ser independientes, ${ }^{1}$ estos deben responder por sus acciones y omisiones. ${ }^{2}$ Así, el fortalecimiento de garantías y arreglos encaminados a garantizar la independencia de los jueces, debe acompañarse de mecanismos óptimos de rendición de cuentas. Diversos estudios a través del mundo se han concentrado en el fenómeno de la independencia. Menos atención ha recibido la obligación de los jueces de dar cuentas de sus actos. ${ }^{3}$ Colombia no ha sido la excepción en cuanto al establecimiento de arreglos institucionales que promuevan la independencia $^{4}$ y la responsabilidad ${ }^{5}$ del poder judicial. Por su parte, son pocos los estudios académicos en el país que se han consagrado al fenómeno de la independencia y al de la rendición de cuenta de los jueces. ${ }^{6}$

1 La bibliografía existente sobre la independencia judicial es extensa: Shetreet, S., \& Deschenes, J. (1985). Judicial Independence: the contemporary debate, Países Bajos: Martinus Nijhoff Publishers. Simon, D. (1985). La independencia del juez, Barcelona: Arial. Díaz, B., \& Linares, S. (2005). Fortalecimiento de la independencia Judicial en Centroamérica: Un balance tras veinte años de reformas. América Latina Hoy: Revista de Ciencias Sociales 39: pp. 47-96. Guarnieri, C., \& Pederzoli P. (1996). La puissance de juger, París: Michalon. Canivet, G.; Andenas, M., \& Fairgrieve, D. (Ed.) (2006). Independence, Accountability and the judiciary, London: British Institute of International and Comparative Law. Burbankand, S., E Friedman, B. (2002). Judicial Independenceat the crossroads: an interdisciplinary approach, California: Sage Publications. Burgos, G. (Ed.), ilndependencia Judicial en América Latina? ¿De quién? ¿Para qué? ¿Cómo?, Bogotá: ILSA.

2 Frente a la relación entre la garantía de la independencia y la necesidad de dar cuentas, en este artículo se acoge la idea de Pérez Perdomo, R. (2001), en su trabajo titulado Independencia y responsabilidad de los jueces. Gestión y análisis de políticas públicas, para quien: "La independencia y la responsabilidad no son características excluyentes, sino características complementarias de la buena justicia" (p. 100).

3 Garoupa, N. \& Ginsburg, T. (2009). Guarding the guardians: Judicial councils and judicial independence. American Journal of ComparativeLaw, 57(1), pp. 103-134.

4 Son varios los mecanismos a través de los cuales se ha buscado dotar al poder judicial colombiano de mayor independencia. Uno de los más importantes fue la exclusión de la participación del ejecutivo y el legislativo en integración del judicial. Me refiero específicamente a la cooptación introducida a mediados del siglo XX. Posteriormente vendrían otras tentativas, más o menos eficaces, como la creación del Consejo Superior de la Judicatura y la implementación de la carrera judicial.

5 En el segundo apartado de este documento me ocupo del conjunto de arreglos previstos en Colombia para hacer a los jueces responsables.

6 Pese a que recientemente han sido publicados estudios que abordan el fenómeno de la independencia y la responsabilidad de los jueces en Colombia, estos análisis siguen siendo escasos. Entre estos se encuentran: Franco, A. (1997). Independencia judicial y política en Colombia. Documento presentado en el encuentro de 1997 de la Latin American Studies Association. Primer borrador. Carrillo, F. (1998). La independencia judicial y su relación con los órganos legislativos. 


\section{En la práctica, es notorio el incremento de acusaciones y escándalos}

vinculados con magistrados de las altas cortes colombianas. También es evidente que el importante número de denuncias contrasta con las demoras en el trámite de expedientes y la ausencia de sanciones. ¿Qué tan responsables son los altos jueces ${ }^{7}$ de la Corte Suprema de Justicia (CS) y del Consejo Superior de la Judicatura en Colombia (CSJ)? Es esta la pregunta que intento responder en este documento. La respuesta que formulo es que, pese a la existencia de un número importante de arreglos institucionales que buscan hacer que los altos jueces den cuentas de sus actos, ${ }^{8}$ estos son débilmente responsables. La fractura en el sistema de control debe rastrearse a partir del funcionamiento inadecuado del órgano que por mandato constitucional

Revista de Derecho (Barranquilla), 9: pp. 1-12. Arrubla Paucar, J. (2007). La independencia del juez y democracia. Revista Facultad de Derecho y Ciencias Políticas, 37(107): pp. 307-310. Instituto Latinoamericano de Servicios Legales Alternativos. (2009). Justicia bajo presión: Constricciones institucionales y atentados contra la independencia judicial en Colombia, 2005-2008, Bogotá, D.C: Instituto Latinoamericano de Servicios Legales Alternativos (ILSA). Rubiano, G. S. (2009). La Corte Constitucional entre la independencia judicial y la captura política. En M. García Villegas \& J. Revelo Rebolledo. Mayorías sin democracia. Desequilibrio de poderes y estado de derecho en Colombia, Bogotá: Dejusticia. García Villegas, M., G Revelo Rebolledo, J. (2010). Estado alterado. Clientelismo, mafias y debilidad institucional en Colombia, Bogotá: DEJUSTICIA. Por su parte, los estudios sobre la responsabilidad de los altos jueces son aún más escasos. Entre estos cabe destacar el realizado por Lamprea, E. (2009).Independencia judicial y rendición de cuentas en la nominación de candidatos a la corte constitucional colombiana. Revista derecho Público, (23): pp. 3-10.

7 Este artículo se inscribe en el marco de una tesis doctoral que, en general, explora el tema de la administración de la justicia en Colombia. La elección de la CS y del CSJ, puede justificarse por el interés de descifrar académicamente, y desde una perspectiva pluridisciplinaria, los efectos de la politización de la justicia y la judicialización de la política en los dos altos tribunales. Es importante resaltar que estas dos altas cortes fueron elegidas como objeto de estudio en el año 2009. En esta época la CS y el CSJ acaparaban la atención de la comunidad académica, medios de comunicación y diversos sectores de la sociedad civil. Esta atención se generó básicamente por dos hechos. De un lado, se hicieron evidentes las consecuencias negativas de confiar a cuerpos políticos la elección de los miembros de la sala disciplinaria del Consejo Superior de la Judicatura. Del otro lado, la Corte Suprema de Justicia llevo a juicio y profirió condenas contra algunos políticos por nexos con grupos al margen de la ley. Al mismo tiempo, las relaciones de este alto tribunal con el gobierno de turno se degradaron; el protagonismo moderado que tenían en este contexto específico la Corte Constitucional y el Consejo de Estado explica su exclusión del análisis propuesto. Teniendo en cuenta las vicisitudes de las relaciones entre la política y la justicia en Colombia, es posible que a la fecha de publicación de este artículo, otra sea la situación de la Corte Constitucional y el Consejo de Estado.

8 La idea de accountability o rendición de cuentas tiene dos dimensiones: de un lado, la obligación de los políticos y los funcionarios de informar sobre sus decisiones y de justificarlas en público, y del otro, la capacidad de sancionar a estos políticos y funcionarios en caso de que violen sus deberes públicos. Léase: Schedler, A. (1999). Conceptualizing accountability. En A. Schdeler, L. Diamondy \& M. F. Plattner (eds.). The self-restraining State: power and accountability in new Democracies (pp.13-28). Boulder, Co: Lynne Rienner. 
controla a los aforados: la Comisión de Investigación y Acusación de la Cámara de Representantes.

Este trabajo se sustenta en la triangulación de diversas fuentes primarias (Bericat, 1998). En este orden de ideas, son varias las fuentes metodológicas $^{9}$ utilizadas en la elaboración de esta investigación. En primer lugar, se encuentra la bibliografía que aborda el tema de la independencia y la rendición de cuentas. Del mismo modo fue leído y analizado un conjunto de normas constitucionales y legales que en Colombia fijan los parámetros de responsabilidad de los jueces, así como algunos pronunciamientos judiciales (sentencias). Además de esta serie de escritos académicos, el presente trabajo se ha nutrido con una vasta revisión de artículos de prensa que hacen alusión a supuestas 'conductas indebidas' de los miembros de la CS y del CSJ. Las noticias recuperadas fueron clasificadas, leídas y analizadas, con el fin de corroborar su pertinencia en el análisis propuesto. Solo en casos puntuales se incluyen extractos de los artículos de prensa. La revisión de artículos de prensa se focalizó en dos diarios y una revista de circulación nacional, a saber: El Tiempo, El Espectador y la revista Semana. También se consultó la información disponible en la Silla Vacía. La revisión de artículos de prensa (un total de 40) abarca el periodo comprendido entre el mes de enero de 2000 y el mes de noviembre de 2013. La elección de este periodo obedeció al hecho de que a partir del año dos mil, la prensa escrita empieza a destacar algunas consecuencias negativas del proceso de selección política de los magistrados de la sala disciplinaria del CSJ. Finalmente, la revisión de artículos de prensa se detiene en el mes de noviembre de 2013, época en la que este artículo fue concluido. Finalmente, este documento tiene en cuenta el análisis estadístico de la información sobre los procesos contra los magistrados, disponible en la página oficial del Congreso de la República en Internet.

Este artículo se organiza de la siguiente manera. En un primer apartado me ocupo de la forma como se concibe la responsabilidad en las dos grandes familias del derecho. El énfasis hecho en la tradición de derecho civil y del common law, se justifica a partir de la importación y adaptación

9 Para el desarrollo metodológico de este artículo se tuvo en cuenta el trabajo de Coffey, A., G Atkinson, P. (2005). Encontrar el sentido a los datos cualitativos: estrategias complementarias de investigación, Alicante: Universidad de Alicante. 
de arreglos institucionales propios de estas dos tradiciones al contexto colombiano. ${ }^{10}$ Es importante destacar que durante mucho tiempo el modelo que fue privilegiado en Colombia fue el del derecho civil. ${ }^{11}$ Esta es la razón por la que en este artículo se privilegia la presentación del caso francés y en menor medida, del italiano. El actual Consejo Superior de la Judicatura, por solo citar un ejemplo, ha sido inspirado en los llamados Consejos de la Magistratura, que a mediados del siglo XX fueron creados en Francia e Italia. Por su parte, la importación de instituciones propias de la tradición del Common law, se incrementa a partir de la expedición de la constitución política de 1991 (Guevara Rivera, 2007). Este hecho puede explicar la adopción en el campo judicial de una visión de eficiencia en la gestión y de la idea anglosajona de la accountability.

En la segunda parte, presento en detalle los mecanismos que en la legislación colombiana buscan que los jueces respondan por faltas de tipo penal y disciplinario. A través de algunos ejemplos muestro cómo este marco normativo es poco eficaz para asegurar un control adecuado sobre la conducta de los altos jueces. En la tercera parte me concentro en una de las principales fracturas del sistema de responsabilidad: la existencia de una Comisión política que investiga y juzga a los altos jueces. Finalmente, concluyo afirmando la ineficacia de los mecanismos directos de rendición de cuentas y resaltando la emergencia de un tipo de control efectivo: el de los mecanismos indirectos e informales de control.

\section{El propósito de la independencia y responsabilidad de los jueces}

Tal y como ocurre con el fenómeno de la independencia, el de la rendición de cuentas está fuertemente emparentado con la tradición jurídica en la que se inscribe un sistema. La tradición determina el tipo de control

10 A propósito de los llamados trasplantes puede leerse el libro de López Medina, D. E. (2004). Teoría impura del derecho. La transformación de la cultura jurídica latinoamericana, Bogotá: Universidad de los Andes, Legis y Universidad Nacional de Colombia.

11 Una exploración de la influencia del constitucionalismo francés en la constitución política 1991 puede leerse en: Guevara Rivera, C. (2007). Análisis de la influencia del constitucionalismo francés en la Constitución Política de 1991. Tesis de grado para optar el título de magíster en derecho, bajo la dirección de Mauricio García Villegas. Bogotá: Universidad Nacional de Colombia. 
ejercido sobre los jueces y sobre todo la forma como es ejercido. Así, a través del mundo los Estados (según se orienten por el common o el civil law) pueden privilegiar como principio la judicial independence o la judicial accountability (Peri, 2012).

La judicial independence privilegia el establecimiento de principios y reglas a través de las cuales se restringe la influencia de otros poderes en las decisiones de los jueces. Los arreglos institucionales que persiguen el objetivo de la independencia pasan, entre otros, por el establecimiento de estrictos criterios de nominación, selección, promoción y duración en el cargo. Se trata de que el juez es sobre todo un funcionario y por ende se somete a la ley, y a fuertes controles de tipo jerárquico y disciplinario (Canivet, $\mathcal{G}$ Joly-Hurard, 2006). Además, debe responder como cualquier ciudadano cuando cometa un delito. En raras ocasiones los jueces en los Estados que privilegian el valor de la judicial independence, responden ante el ejecutivo, el legislativo o la ciudadanía en general. También son escasos los países que en esta tradición han buscado fortalecer la judicial accountability, a través de parámetros derivados del new public management. ${ }^{12} \mathrm{El}$ principal reparo que se hace al incremento de la rendición de cuentas es que puede acarrear una disminución de la independencia y de la imparcialidad del juez.

Por su parte, la judicial accountability se relaciona con la entrega de cuentas en una relación. De hecho, esta expresión es una de la cuestiones claves del new public management. En este contexto se busca promover la eficiencia, el control de costos y optimizar los resultados de la gestión (Contini E Mohr, 2007). Desde esta perspectiva, el juez más que la boca de la ley, es concebido como un actor que juega un rol dentro de la organización pública prestando un servicio al público (Contini \& Mor, 2007). Así, el juez debe dar cuenta de las normas escritas, sobre todo a la sociedad y a las instituciones democráticas.

La rendición de cuentas es privilegiada en los países que siguen la tradición del common law, en la que existe una imagen valorizada de un juez prestigioso que llega al cargo luego de un proceso riguroso. Este juez

12 Cabe destacar que pese a esta reticencia, países como España, Italia y Finlandia han adoptado recientemente, y con diversos resultados medidas ligadas, la new public management en sus sistemas judiciales. Ver Contini, F., E Mohr, R. (2007). Reconciling independence and accountability in judicial systems. Utrecht Law. Review, 3, pp. 26-43; Frydman, B., \& Jeuland E. (2011). Le nouveau management de la justice et l'indépendance des juges, Paris: Dalloz. 
integraría una élite social e intelectual, por lo que su error sería apenas concebible (Canivet, \& Joly-Hurard, 2006). Esta idea no impide que los jueces respondan por sus acciones y sean disciplinados. En Estados Unidos, por ejemplo, se establece que los jueces federales permanecen en sus cargos mientras observen buena conducta. Esta prescripción se traduce en la permanencia vitalicia en sus cargos. Sin embargo, estos altos jueces pueden ser removidos de sus cargos a través del procedimiento legislativo del impecheament, ${ }^{13}$ cuyo uso en la práctica es raro.

Por su parte, a nivel estatal se han establecido comisiones de disciplina judicial y remoción. Sin embargo la responsabilidad de los jueces en esta tradición no solo se traduce en la posibilidad de ser disciplinados, sino en el hecho de que deban rendir cuentas a la sociedad sobre sus acciones. En los Estados Unidos, dado que el Congreso tiene un amplio poder para decidir sobre el presupuesto ${ }^{14}$ y sobre la organización judicial, el poder judicial se obliga a presentar un informe sobre la utilización óptima de recursos (Gur-Arie \& Wheeler, 2002). Del mismo modo, la presentación de informes estadísticos hace que los jueces den cuenta sobre la eficacia de su gestión. En algunos casos se ha denunciado cómo a través de estos procesos de rendición de cuentas, el legislativo y el ejecutivo pueden incidir en la decisión de los jueces, y por ende en su independencia.

En suma se trata de que el juez en las dos grandes familias del derecho está llamado a rendir cuentas por sus acciones y omisiones. A continuación presento en detalle las formas en que puede revestir la responsabilidad.

La responsabilidad disciplinaria. En general, este tipo de responsabilidad persigue la violación o el desconocimiento de las faltas frente a deberes profesionales, reglas deontológicas y principios éticos. Así, se acepta que los jueces pueden faltar a sus deberes no solamente cuando ejercen sus funciones, sino a través de conductas inscritas en el ámbito de su vida privada. En este caso, se puede tratar de atentados contra la imagen o la

13 Entre las bases de este procedimiento se encuentran: traición, soborno, crímenes graves y delitos menores.

14 A nivel estatal se han reportado casos en los que el presupuesto de las Cortes estatales han sido disminuidos por decisiones impopulares frente al gobernador o la legislatura. En Schauffler, R. (2007). Judicial Accountability in the US State Courts: Measuring Court, Performance. Recuperado de http://www.utrechtlawreview.org/index.php/ulr/article/view/URN\%3ANBN\%3ANL\%3AUI\%3A 10-1-101059/40 Consulta realizada el 10 de septiembre de 2013. 
reputación de la institución judicial, como ha sido previsto en el caso de Italia y Francia. En este último país, en principio, se prevé que las manifestaciones de la vida privada del juez no relevan una acción disciplinaria. Sin embargo, cuando los comportamientos privados atentan ${ }^{15}$ contra el 'crédito y la confianza de los justiciables', la inmunidad del juez se diluye.

Algunos de los actos privados que los jueces en este país están llamados a evitar son: ${ }^{16}$ los gestos de violencia contra funcionarios, auxiliares y usuarios de la justicia, las relaciones afectivas o de amistad, esto es, las frecuentaciones públicas; ${ }^{17}$ los compromisos religiosos, políticos, contractuales o sindicales cuando estos son la causa del ausentismo exagerado, y el retardo en las labores judiciales.

Un tipo de actos que se encuentran, en principio, excluidos de control disciplinario, son los actos jurisdiccionales. Sin embargo, como en el caso de los actos de la vida privada, existen ciertas excepciones, como cuando el juez en su sentencia, contra las apariencias, profiere un acto extraño a toda actividad jurisdiccional. ${ }^{18}$ Por ejemplo, cuando en la redacción del juzgamiento emplea términos inútiles, particularmente duros o violentos, inapropiados, irrespetuosos, extravagantes, groseros y racistas. ${ }^{19}$

15 El Conseil Superior de la Magistrature Francés se ha manifestado sobre el particular afirmando que: "Cette règle trouve cependant un tempérament lorsque le comportement privé du magistrat donne lieu à des débordements pouvant avoir un retentissement sur l'exercice professionnel ou risquant de dégrader l'image de sa fonction». Ver Francia, Conseil Supérieur de la Magistrature, rapportd'activité 2002-2003, (période du 5 juin 2002 au 31 août 2003).

16 Los ejemplos concretos de los comportamientos privados que oscurecen la acción del juez son detallados por Canivet, G., E Joly-Hurard J., (2009). La déontologie du magistrat, París: Dalloz.

17 El Conseil Supérieur de la Magistrature ha considerado que caracterizan una falta profesional, susceptible de acciones disciplinarias, las relaciones de amistad cuando conducen "compromettre gravement l'independence du magistrat dans la citê" Véase Commaret, D., (2000). Les responsabilités déontologiques des magistrats á la lumière de la jurisprudence du Conseil Supérieur de la magistrature, En Association française pour l'histoire de la justice, (Ed. scientifique). Juger les Juges. Du Moyen Age au Conseil Supérieur de la Magistrature. Paris: La documentation Française.

18 Ver: Francia. Conseil Supérieur de la Magistrature, rapport d'activité 2002-2003 (période du 5 juin 2002 au 31 août 2003).

19 En Colombia, también se han excluido los actos jurisdiccionales (interpretar la norma y adoptar decisiones) del control disciplinario. La excepción a esta regla se configura cuando la discrecionalidad se trasforma en arbitrariedad o se emiten decisiones que contrarien o desatiendan textos legales cuya claridad no admita interpretación razonable. Este es el criterio sostenido por la Corte Constitucional en sus fallos. Sobre el particular léase: Sentencia C-417 de 1993, M.P. José Gregorio Hernández; T-249 de 1995, M.P. Hernando Herrera Vergara; T-625 de 1997, M.P. José Gregorio Hernández Galindo; T-056 de 2004, M.P. Marco Gerardo Monroy Cabra. 
En los países con tradición continental suele existir un órgano encargado de asegurar la disciplina de los jueces: el Consejo Superior de la Magistratura. Esta institución puede tener una integración mixta, en la que se incluyen miembros de la magistratura, pero también personas que vienen de diversos medios. Esta composición mixta es notablemente el caso de Italia. En Francia, el Consejo Superior de la Magistratura puede considerarse como de carácter mixto. Otros países han preferido confiar la disciplina de sus jueces a un órgano integrado exclusivamente por personas del medio judicial. ${ }^{20}$

Las faltas disciplinarias. La garantía de independencia y el control sobre de la disciplina de los jueces se ha encomendado en ciertos países a los Consejos Superiores de la Magistratura (Renoux, 2000). Para cumplir sus fines, estas instituciones se orientan por normas especialmente previstas para tal fin. En países como Francia, existe un statut de la magistrature, en el cual se define lo que constituye una falta disciplinaria. En este país la ordenanza n. ${ }^{\circ}$ 58-1270 de diciembre 22 de 1998 define la falta disciplinaria como:21" tout manquent par un magistrat aux devoirs de son état, a l'honeur, a la délicatesse a la dignité constituant une faute disciplinaire". A lo anterior se suman una serie de deberes profesionales del orden deontológico que son compatibles con el estatuto arriba enunciado (Canivet \& Joly-Hurard, 2009).

Aunque la imposición de sanciones por faltas disciplinarias es el ejercicio que predomina en muchos países (incluido Colombia), otros han optado por conjugar la prevención y la sanción. Esta estrategia pasa por un conjunto de políticas y acciones encaminadas a fortalecer en el cuerpo judicial la concienciación sobre la importancia de su misión y la imagen que de esta envían a la sociedad. En la práctica, se ha resaltado cómo la conciencia elevada sobre valores deontológicos pasa por las buenas prácticas en el reclutamiento y la formación inicial y continua de los jueces (Canivet $\mathcal{E}$ Joly-Hurard, 2009). Además, pueden ser de gran utilidad las acciones que buscan recompensar a "los buenos jueces". 22 En Francia estas acciones se

20 La renuencia a aceptar este tipo de composición de los consejos es amplia. La principal razón de esta reticencia se encuentra en el alto riesgo de corporativismo que implica tal integración.

21 Esta definición ha sido acogida para los funcionarios del orden judicial. Ver Canivet, G., E Joly-Hurard J. (2009). La déontologie du magistrat, París: Dalloz.

22 En Francia esta iniciativa se ha traducido en la asignación a los magistrados de indemnidades que remuneran la importancia y el valor de los servicios prestados; se trata de una prima al mérito. 
han traducido en la prima al mérito y en la firma de contratos de objetivos. ${ }^{23}$ Del mismo modo, se ha resaltado la importancia de adoptar códigos de deontología y órganos de reflexión, que sensibilicen al cuerpo judicial sobre los problemas ligados a la ética profesional.

Responsabilidad Penal. Generalmente se acepta a través del mundo que los jueces responden por delitos o infracciones a la ley penal. En algunos casos, los Estados tipifican de manera concreta conductas delictivas en las que pueden incurrir los jueces en ejercicio de sus funciones. En esta medida, las legislaciones penales suelen prever un apartado de los llamados delitos contra la administración de justicia: peculado, corrupción, abuso de autoridad, violación del secreto profesional y negación de justicia. Este es el caso de países como España (Durand, 2003) en donde el código penal, establece una sección de delitos contra la administración de justicia, dentro de los cuales se encuentra la prevaricación.

En otros países los jueces pueden responder por sus infracciones como cualquier otro funcionario (Bélgica o Italia) o como cualquier otro ciudadano (Francia). En este último caso, los jueces no gozan de ningún privilegio de jurisdicción ni de inmunidad luego de la ley n. ${ }^{\circ}$ 93-2 del 4 de Enero de 1993. Así, los jueces en este país, pueden ser perseguidos penalmente, como cualquier otro ciudadano, en nombre del principio de igualdad de todos ante la ley (Canivet \& Joly-Hurard, 2006).

Algunos países han reconocido un sistema de inmunidad para los jueces, que puede ser de tipo sustancial o procesal (Canivet, 2003). En la primera categoría se encuentra una prohibición de seguir a los jueces por actos u omisiones relacionados directamente con su función de juez, como es el acto de proferir una sentencia. Dentro de las inmunidades de carácter procesal, se encuentran aquellas orientadas a que el inicio de la acción de responsabilidad penal requiera una autorización previa o que se realice por autoridades estrictamente designadas (Canivet, 2003). Aunque los estudios comparados muestran que la tendencia en las dos tradiciones privilegia la idea de que los jueces deben responder penalmente, en la práctica estos casos son atípicos.

23 Estos contratos buscan reducir los tiempos de juzgamiento en contrapartida de una locación de medios materiales y humanos a la jurisdicción contratante. 
Luego de este rápido vistazo a la forma como las dos grandes tradiciones buscan responsabilizar a sus jueces, me ocupo del caso colombiano. Anticipo que una mezcla de características de las dos tradiciones analizadas se encuentra en el país.

\section{La responsabilidad de los altos jueces en Colombia}

En este segundo apartado detallo la manera como en la legislación colombiana se prevé que los jueces respondan por sus acciones y omisiones. Concretamente, me ocupo de dos formas de responsabilidad: la disciplinaria y la penal. Luego de presentar el marco normativo, me concentro en algunos casos emblemáticos en los que los magistrados de la Corte Suprema de Justicia y el Consejo Superior de la Judicatura se han visto involucrados en acciones que, presuntamente, vulneran normas de tipo disciplinario o penal. Advierto que una ejemplificación de este tipo es problemática, ${ }^{24}$ por lo que los casos mostrados son aquellos que han sido altamente mediatizados y objeto de pronunciamiento por entes oficiales.

En Colombia se observa la directriz a afianzar las garantías de la independencia externa e interna de los jueces. El punto culminante de esta tendencia fue la expedición de la Constitución Política de 1991, a través de la cual se introdujo un diseño que aparta al poder judicial de indebidas influencias. Del mismo modo, se encuentra en el sistema jurídico colombiano un conjunto de normas a través del cual se busca que todos los jueces de la República respondan por sus acciones y omisiones.

Las formas como los jueces responden, varían en función de su jerarquía. Así, las faltas cometidas por los altos jueces en Colombia (dada su condición de aforados) son conocidas por la Comisión de Investigación y Acusación de la Cámara.

Por su parte: jueces, magistrados de tribunales y demás funcionarios del poder judicial son responsables civil, penal y disciplinariamente. Este último control es ejercido actualmente por la Sala Disciplinaria del Consejo Superior de la Judicatura siguiendo los parámetros establecidos por normas

24 Hasta el momento de redacción del presente artículo no existen condenas de tipo penal ni sanciones de tipo disciplinario proferidas contra los magistrados de las altas cortes. 
como el Código Disciplinario Único y la Ley Estatuaria de la Administración de Justicia. La indagación y el castigo por la responsabilidad penal suelen estar en manos de la justicia ordinaria. En la tabla 1 se ilustran los tipos de responsabilidad y las entidades ante las cuales responden los jueces, según su nivel jerárquico.

Tabla 1. Responsabilidad penal y disciplinaria de los altos jueces en Colombia

\begin{tabular}{|l|l|l|}
\hline \multicolumn{1}{|c|}{ Organismo } & \multicolumn{1}{|c|}{ Tipo de responsabilidad } & \multicolumn{1}{c|}{ Juez natural } \\
\hline $\begin{array}{l}\text { Magistrados de la Corte Suprema } \\
\text { de Justicia }\end{array}$ & $\begin{array}{l}\text { - Responsabilidad penal } \\
\text { Responsabilidad } \\
\text { disciplinaria }\end{array}$ & $\begin{array}{l}\text { - Comisión de Investigación y } \\
\text { Acusación de la Cámara de } \\
\text { Representantes } \\
\text { Eventualmente Corte } \\
\text { Suprema de Justicia }\end{array}$ \\
\hline $\begin{array}{l}\text { Magistrados del Consejo Superior } \\
\text { de la Judicatura }\end{array}$ & $\begin{array}{l}\text { - Responsabilidad penal } \\
\text { Responsabilidad } \\
\text { disciplinaria }\end{array}$ & $\begin{array}{l}\text { - Comisión de Investigación y } \\
\text { Acusación de la Cámara de } \\
\text { Representantes } \\
\text { Eventualmente Corte } \\
\text { Suprema de Justicia }\end{array}$ \\
\hline $\begin{array}{l}\text { Jueces y magistrados de los } \\
\text { Tribunales Superiores del distrito } \\
\text { Judicial }\end{array}$ & $\begin{array}{l}\text { Responsabilidad } \\
\text { disciplinaria }\end{array}$ & $\begin{array}{l}\text { Consejo Superior de la } \\
\text { Judicatura }\end{array}$ \\
\hline $\begin{array}{l}\text { Jueces y magistrados de los } \\
\text { Tribunales Superiores del distrito } \\
\text { Judicial }\end{array}$ & Responsabilidad penal & Justicia ordinaria \\
\hline
\end{tabular}

Fuente: elaboración propia.

\subsection{Responsabilidad disciplinaria}

En Colombia las acciones y omisiones que pueden catalogarse como faltas disciplinarias están previstas en textos como el Código Disciplinario Único y la Ley Estatutaria de la Administración de Justicia. El Código Disciplinario Único ${ }^{25}$ contempla un apartado que trata sobre el régimen de los funcionarios de la rama judicial. ${ }^{26}$ La falta disciplinaria es definida por este código como: "(...) el incumplimiento de los deberes y prohibiciones, la incursión en las inhabilidades, impedimentos, incompatibilidades y conflictos de

25 Véase ley 734 de 2002.

26 Los funcionaros con fuero se encuentran excluidos de este control disciplinario. Como he resaltado a lo largo del texto, esto incluye, entre otros, a los magistrados de las altas Cortes. 
interés previstos en la constitución, en la ley estatutaria de administración de justicia $y$ demás leyes" ${ }^{27}$ Este estatuto enumera las faltas disciplinarias en particular, haciendo una clasificación entre faltas gravísimas, graves o leves. Del análisis de la primera categoría, esto es las faltas gravísimas, se puede afirmar que son hechos que se mueven entre la falta disciplinaria y el delito. Entre este tipo de infracciones se encuentran: extraviar, perder o dañar bienes del Estado, incrementar injustificadamente el patrimonio, obstaculizar investigaciones que adelanten las autoridades administrativas, jurisdiccionales o de control, ocasionar la muerte a un grupo nacional, étnico, racial, político o religioso, incurrir en violaciones al derecho internacional humanitario y privar ilegalmente de la libertad a una persona.

En lo que se refiere a la tipificación de las faltas, el Código Disciplinario Único remite a la Ley Estatutaria de Administración de Justicia. ${ }^{28}$ Esta norma, al ser más específica, enumera los deberes y las prohibiciones propias de los funcionarios y empleados de la rama judicial. El conjunto de deberes contiene algunas prescripciones de carácter general y otras ligadas estrechamente al ejercicio de funciones judiciales. En la primera categoría (prescripciones de carácter general), según la Ley Estatutaria de la Administración de la Justicia, en su artículo 153, se encuentran: cumplir la Constitución y las leyes, desempeñar con honorabilidad, solicitud, celeridad, eficiencia, moralidad, lealtad e imparcialidad las funciones a su cargo. En el segundo tipo de normas (las específicas que prevén deberes), se encuentran entre otras: la obligación de guardar reserva de los asuntos conocidos aún después de haber cesado en el ejercicio del cargo, declarar en ciertas circunstancias las variaciones importantes del patrimonio, dedicarse exclusivamente a la función judicial, ${ }^{29}$ evitar la lentitud procesal y sancionar todas aquellas maniobras dilatorias.

Del mismo modo, la Ley Estatutaria de la Administración de Justicia, en su artículo 154, prevé un conjunto de prohibiciones entre las que se encuentran: realizar actividades ajenas al ejercicio de su trabajo durante

27 Artículo 196 ley 734 de 2002.

28 Véase Ley 270 de 1996.

29 La única excepción permitida por la legislación colombiana a esta regla es el ejercicio de la docencia o la investigación científica. En todo caso la dedicación a estas labores no puede exceder un número determinado de horas. Ver Colombia, Ley estatutaria de la Administración de Justicia, Ley 270 de 1996, Diario oficial 42.745 del 15 de marzo de 1996, artículo 151. 
la jornada laboral, abandonar sus labores sin autorización previa, embriagarse periódicamente y utilizar sustancias prohibidas por la ley, retardar o negar injustificadamente el despacho de los asuntos conocidos, proporcionar noticias o informes sobre asuntos de la administración de justicia que conozcan, participar en procesos electorales, realizar en el servicio o en la vida social actividades que afecten la confianza del público u observar conductas que comprometan la dignidad de la administración de justicia, recibir remuneraciones de los interesados en un proceso, aceptar donaciones, obsequios, atenciones, agasajos o sucesión testamentaria de las partes o de sus apoderados. Estas son, en síntesis, las dos principales normas que encuadran el comportamiento de los funcionarios y empleados del poder judicial en Colombia.

A lo anterior ha de sumarse un cúmulo de sentencias ${ }^{30}$ de la Corte Constitucional colombiana, a través de las cuales se han diseñado líneas jurisprudenciales claras y que son de fácil acceso para los miembros del judicial y para cualquier ciudadano. Menos publicitadas y de acceso más complicado son las sentencias emitidas por la Sala Jurisdiccional Disciplinaria y los Consejos Seccionales de la Judicatura. La falta de visibilidad de su jurisprudencia supone un problema para que los operadores judiciales y el público en general puedan conocer, reflexionar e interiorizar las reglas legales y los principios deontológicos

\section{Comentarios sobre el origen de la responsabilidad disciplinaria en Colombia}

La existencia de un cuerpo con funciones jurisdiccionales encargado de sancionar disciplinariamente a jueces y magistrados fue admitido con muchos reparos en el sistema judicial colombiano. A este sistema de control se llegó luego de haberlo confiado al superior jerárquico, a las comisiones disciplinarias, a la Procuraduría y a los jurados de honor. La adjudicación del control en estos cuerpos debió remplazarse por adolecer de vicios burocráticos.

30 El poder sancionatorio en materia disciplinaria ha sido encomendado al Consejo Superior de la Judicatura. Sin embargo, la Corte Constitucional en sus fallos de tutela y en algunas demandas de constitucionalidad ha sentado parámetros jurisprudenciales en temas como la autonomía e independencia de los jueces y el ejercicio del control disciplinario de la función judicial. 
La creación de un Tribunal Disciplinario (antecesor del Consejo Superior de la Judicatura), llamado por algunos 'Súper Corte', se remonta al comienzo de la década de los sesenta. Según el Decreto 1698 de 1964, este Tribunal conocía, en única instancia, de los procesos por faltas disciplinarias adelantadas contra magistrados de la Corte Suprema y del Consejo de Estado y en segunda instancia, de los procesos por faltas disciplinarias fallados en primera instancia por la Corte Suprema de Justicia, el Consejo de Estado, los Tribunales Superiores de Distrito judicial y por el Tribunal de Aduanas. Estas atribuciones fueron objeto de control de constitucionalidad por parte de la Corte Suprema de Justicia. En su decisión, el máximo tribunal de la justicia ordinaria decretó la inexequibilidad de la prescripción, al considerar que no era aceptable que los jueces fueran juzgados por un ente que no fuera su superior.

La iniciativa de fundar este tipo de tribunal renació en la reforma constitucional de 1968. El Tribunal Disciplinario, esta vez de rango constitucional, tenía bajo su control las faltas cometidas por los funcionarios judiciales ${ }^{31} \mathrm{y}$ ofrecía garantías procesales plenas para los investigados. Además, conocía de las faltas contra la ética de los abogados y dirimía conflictos de competencia que se desataran entre diferentes jurisdicciones. Sus miembros, elegidos para periodos de 5 años, debían cumplir los mismos requisitos que para ser elegido en el cargo de magistrado de la Corte Suprema y eran elegidos por el Congreso de la República de ternas presentadas por el Presidente de la República.

La recepción de un Tribunal de estas características y con estas funciones no fue de buen recibo en la cúpula del poder judicial. El malestar que generó este nuevo tribunal, pudo estar al origen del pronunciamiento de la Corte Suprema de Justicia el 21 de Octubre de 1976. Mediante su decisión ${ }^{32}$ la máxima instancia de la Justicia ordinaria restringió las facultades del Tribunal Disciplinario que en adelante solo disciplinaría a sus propios magistrados, a los del Consejo de Estado, Tribunales Superiores de distrito

31 El artículo 217 del acto legislativo n. 1 de 1968 estableció que: "El conocimiento de las faltas disciplinarias de los magistrados de la Corte Suprema de Justicia y del Consejo de Estado, corresponde al Tribunal Disciplinario, el cual está encargado de dirimir los casos de competencia que ocurran entre la jurisdicción común y la administrativa(...)".

32 En esta oportunidad la Corte Suprema de Justicia fue enfática en recalcar que solo los superiores podían juzgar a los inferiores. 
judicial, aduanas y contencioso administrativo ${ }^{33}$. El Tribunal Disciplinario con funciones ampliamente reducidas pereció en 1991, cuando fue remplazado por el Consejo Superior de la Judicatura.

\subsection{Responsabilidad Penal}

Como arriba anoté, jueces y magistrados en Colombia están llamados por la ley a responder por sus infracciones a la ley penal. La indagación y el castigo por este tipo de responsabilidad suelen estar en manos de la justicia ordinaria. Existe, por ejemplo, un apartado en el Código Penal colombiano que se ocupa de los delitos y transgresiones contra la administración de justicia. Por su parte, la competencia para conocer de este tipo de conductas ha sido, por ley, confiada a diferentes autoridades. Los altos magistrados, gracias a su fuero, son investigados por la Comisión de Investigación y Acusación de la Cámara, y eventualmente juzgados por la más alta instancia de la justicia ordinaria: la Corte Suprema de Justicia. Por su parte, las infracciones de tipo penal cometidas por los jueces de inferior jerarquía son de conocimiento de la justicia ordinaria.

Es importante subrayar que la única sanción de tipo disciplinario contra un alto magistrado fue emitida contra un miembro de la sala penal (Domínguez, 1981). En efecto, en el año 1976 un magistrado en el cargo fue destituido por el Tribunal Disciplinario al considerarse que había cometido una falta contra la administración de justicia. El asunto se inició por dos supuestas llamadas telefónicas hechas por el entonces miembro de la Corte Suprema de Justicia. En la primera habría preguntado a un magistrado de inferior jerarquía sobre la doctrina probable frente a un caso. En la segunda llamada, el alto juez habría solicitado a un magistrado del Tribunal Superior estudiar personalmente un negocio. La historia finalizó con la nulidad de la actuación del Tribunal Disciplinario, decretada en 1980 por el Consejo de Estado. A juicio de este alto tribunal, la decisión habría sido proferida por una autoridad que carecía de competencia: el Tribunal Disciplinario.

33 Esta decisión de la Corte Suprema fue abiertamente criticada porque: "habría convertido una gran organización, una importante organización, en un Tribunal de muy escasa importancia, que es lo que efectivamente tenemos hoy entre manos". Véase Intervención de Rodolfo García Ordóñez en Revista del Tribunal Disciplinario. Enero de 1986 a Diciembre de 1991. 
El asunto, entonces, era de competencia de la Comisión de Investigación y Acusación de la Cámara de Representantes y del Senado de la República. Luego de este breve repaso sobre la forma en la que responden penalmente los altos jueces, reseño algunas denuncias por presuntos delitos cometidos por los magistrados.

\section{Denuncias por presuntos delitos cometidos por los altos jue-}

ces. El escaso número de "casos juzgados" (Domínguez, 1981) contrasta con la cantidad creciente de denuncias de faltas de carácter disciplinario y penal de los magistrados de las altas Cortes. El incremento de cuestionamientos al comportamiento frente a sus deberes como juez y, en general, en su vida privada, se constata en una simple revisión de los expedientes conocidos por la Comisión de Investigación y Acusación de la Cámara de Representantes, y el amplio número de artículos de prensa sobre el tema. ${ }^{34}$

34 La ausencia de estudios académicos y estadísticas oficiales sobre el tema contrasta con la gran cantidad de páginas dedicadas por diferentes medios de comunicación a este tipo de denuncias. Véase: Proceso contra campo soto, (4 de julio de 2000), El Tiempo. Despilfarro en la judicatura, (28 de septiembre de 2000). El Tiempo. Comisión de acusación tiene el caso. Magistrada denunciada por sus colegas, (23 de mayo de 2003), El Tiempo. El juez y la mafia, (25 de noviembre de 2006). El Tiempo. Amistades peligrosas, (02 de diciembre de 2006). Semana. Denuncia penal de Uribe contra presidente de la Corte Suprema de Justicia, (18 de enero de 2008), El Tiempo. Uribe demandara por injuria y calumnia al presidente de la Corte, (18 de enero de 2008), El Espectador. Gobierno contra ataca a Corte Suprema con denuncia a sus magistrados, (27 de junio de 2008), El Tiempo. Sorpréndase: mi vida social ha sido siempre muy restringida (12 de julio de 2008), El Espectador. Magistrados preocupa su elección, (30 de agosto de 2008), El Espectador. Ovidio claros, nuevo magistrado del Consejo Superior de la Judicatura está demandado por alimentos ( 8 de septiembre de 2008), El Tiempo. Orozco, C., (10 de octubre de 2008). Denuncié a cuatro magistrados del Consejo Superior de la Judicatura, El Espectador. Coronell, D. (11 de abril de 2009). Un magistrado en Problemas, Semana. La red del Consejo de Estado, (05 de septiembre de 2009), El Espectador. Las llamadas de los magistrados que la procuraduría pide investigar, (06 de septiembre de 2009), El Espectador. Acusaciones enfrentan a la sala administrativa con la disciplinaria de la Judicatura, (11 de Enero de 2012), El Espectador. Denuncian sobrecostos en contratación en Sala Administrativa de la Judicatura, (11 de enero de 2012), El Espectador. Choque de trenes por investigación de carrusel de nombramientos, (16 de febrero de 2012), El Tiempo. Abren proceso de responsabilidad fiscal contra nueve magistrados, (7 de marzo de 2012), El Espectador. Senadores y magistrados admiten tener familiares en la procuraduría, (10 de octubre de 2012), El Espectador. Necesitamos mejores magistrados: Presidenta de la Judicatura, (28 de octubre de 2012), El Tiempo. ¿Quién frena a los magistrados?, (17 de noviembre de 2012), El Tiempo. Orozco, C. (04 de mayo de 2013). Entrevista a Néstor Raúl Correa, El Espectador. Este sábado llegan a Cartagena los magistrados de polémico crucero, (24 de mayo de 2013), El Tiempo. Fin del carrusel de pensiones, (25 de mayo de 2013), El Espectador. Piden embargar sueldo de la magistrada María Mercedes López, (19 de junio de 2013), El Tiempo. Fiscalía reveló pruebas en carrusel por pensiones, (09 de agosto de 2013), El Espectador. Archivan investigación a secretaria de la Judicatura por carrusel de pensiones, (27 de agosto de 2013). El Espectador. Las pistas que destaparon el cartel de los magistrados de Paloquemao, (19 de octubre 
Aunque a través del mundo se ha reseñado la rareza de las sanciones contra los altos jueces, el caso colombiano llama especialmente la atención por dos razones. La primera, es que al contrario de lo que ocurre en países que privilegian la tradición del commonlaw, los altos jueces en Colombia (especialmente los miembros de la sala disciplinaria del Consejo Superior de la Judicatura) no gozan en todos los casos de una imagen de prestigio ni llegan a su cargo luego de un proceso de selección riguroso. ${ }^{35}$ La segunda razón por la que la rareza de las sanciones contra los altos jueces llama la atención, es porque en la comisión de Investigación y Acusación anidan inconvenientes ${ }^{36}$ que dificultan su gestión y minan su legitimidad.

\section{Debilidades en el ente que investiga las faltas de los altos jueces}

Este último apartado está consagrado a la Comisión de Investigación y Acusación de la Cámara de Representantes. Inicio el análisis haciendo énfasis en los principales problemas que actualmente aquejan a esta célula legislativa. Estos inconvenientes están relacionados con: el procedimiento previsto para tramitar los expedientes y con el personal que conforma la Comisión de Investigación y Acusación. En seguida, muestro los resultados de la gestión de la Comisión de Investigación y Acusación. Estos se traducen en el considerable número de expedientes que (luego de muchos años)

de 2013), El Tiempo. Las grabaciones que incomodan al magistrado Villarraga, (27 de octubre de 2013), El Espectador. El otro escándalo del magistrado Villarraga, (28 de octubre de 2013), Semana.

35 Los procesos actuales de nominación y selección de magistrados en la Corte Suprema de Justicia y el Consejo Superior de la Judicatura han sido objeto de fuertes críticas. En el caso de la primera institución, se han resaltado inconvenientes ligados a la intervención de la Sala Administrativa en la elaboración de listas de Candidatos. Por su parte, los reproches hechos al proceso de nominación y selección de miembros de la sala disciplinaria del Consejo Superior de la Judicatura, se concentran en la competencia para nominar y seleccionar confiada al Presidente y al Congreso de la República. Sobre este último caso léase Revelo Rebolledo, J. (2009), El Consejo Superior de la Judicatura entre eliminación y cooptación. En M. García Villegas \& J. Revelo Rebolledo (eds.), Mayorías sin democracia. Desequilibrio de poderes y Estado de derecho en Colombia 2002-2009, (pp. 248281). Bogotá: Dejusticia.

36 A estos problemas se suma el desprestigio que en ciertos momentos ha ensombrecido al Congreso colombiano, como fue el escándalo de la parapolítica. Léase López Hernández, C., \& Ávila Martínez, A. (2010). Y refundaron La Patria: de cómo mafiosos y políticos reconfiguraron el Estado colombiano. Bogotá: Debate. 
aún se encuentran en "preliminares" y la gran cantidad de conductas que aún no han sido tipificadas. Son estas falencias en la gestión y resultados los que contribuyen a consolidar la percepción de una 'responsabilidad atenuada' de los altos jueces de la Corte Suprema de Justicia y del Consejo Superior de la Judicatura.

\subsection{Algunas observaciones sobre la Comisión de Investigación y Acusación de la Cámara de Representantes}

En Colombia, la Constitución Política de 1991 confió al Congreso la facultad de investigar y acusar a algunos de los altos funcionarios. ${ }^{37} \mathrm{El}$ trámite que se surte en Cámara y Senado se aproxima a la idea de un juicio político. La constitución también reconoce la posibilidad de que, tratándose de delitos comunes, el procedimiento pueda ser conocido por la Corte Suprema de Justicia. En este caso la sanción aplicable es la prevista por la ley penal. Las críticas que recaen sobre este procedimiento se concentran en su fase en la Cámara de Representantes (López Daza, 2010). Se debe tener en cuenta que desde hace más de 50 años ningún alto funcionario ha sido llevado ante el Senado. Por su parte, los eventuales inconvenientes ligados al desarrollo de un eventual juicio ante la Corte Suprema de justicia son una incógnita: a la fecha, ningún procedimiento ha llegado a esta instancia.

A continuación reseño la forma como se surte el procedimiento de investigación de altos funcionarios en la Cámara de Representantes. En seguida presento algunas de las críticas más frecuentes al mismo.

\section{Los Trámites en la Comisión de Investigación y Acusación.} A semejanza del impeachment, ${ }^{38}$ en Colombia las tareas de investigación

37 El artículo 178 de la Constitución Política de 1991 establece que corresponde a la Cámara de Representantes: "'Acusar ante el Senado, cuando hubiere causas constitucionales, al Presidente de la República o a quien haga sus veces, a los magistrados de la Corte Constitucional, a los magistrados de la Corte Suprema de Justicia, a los miembros del Consejo Superior de la Judicatura, a los magistrados del Consejo de Estado y al Fiscal General de la Nación'. Por su parte el artículo 174 establece que corresponde al Senado: 'conocer de las acusaciones que formule la Cámara de Representantes contra el Presidente de la República o quien haga sus veces; contra los Magistrados de la Corte Suprema de Justicia, del Consejo de Estado y de la Corte Constitucional, los miembros del Consejo Superior de la Judicatura y el Fiscal General de la Nación, aunque hubieren cesado en el ejercicio de sus cargos. En este caso, conocerá por hechos u omisiones ocurridos en el desempeño de los mismos'".

38 Este modelo de investigación y juicio, esencialmente político, fue fijado en algunos apartes 
y el juzgamiento de altos funcionarios han sido confiadas a la Cámara de Representantes y al Senado. Así, en la Cámara de Representantes existe una comisión de carácter permanente denominada Comisión de Investigación y Acusación. ${ }^{39}$

La investigación en esta instancia puede ser iniciada de oficio, por una denuncia o por el informe de una autoridad. De su conocimiento se ocupan 15 miembros del Congreso, elegidos por el sistema de cociente electoral. ${ }^{40}$ Las denuncias pueden ser instauradas por delitos cometidos en el ejercicio de funciones, por indignidad, mala conducta o por delitos comunes. Cuando la Comisión de Investigación y Acusación encuentra mérito, prepara proyectos de acusación (que deberá aprobar el pleno de la Cámara) y eventualmente acusa ante el Senado.

En esta instancia se da inicio a la etapa de juicio. Si la acusación se refiere a delitos comunes, se citará al acusado y se le pondrá a disposición de la Corte Suprema de Justicia. Aunque en teoría este sistema puede ocasionar que los miembros de la Corte Suprema juzguen a sus propios magistrados, en la práctica nunca se ha presentado esta situación.

El estudio realizado por López Daza (2010) ilustra muy bien cómo recientemente ninguna alta corte ha escapado a denuncias contra uno o varios de sus miembros. No obstante, el número de procesos contra miembros de las altas cortes varía notablemente. De un lado, la Corte Suprema de Justicia es la instancia que en el año 2010 tenía más procesos contra sus magistrados: 180 (Castillo, 2010). Casi la mitad de estos procesos estaban dirigidos contra miembros de la sala penal. Esta abundancia, puede explicarse a partir de los choques constantes del alto tribunal (sala penal) con el gobierno del

del texto constitucional de los Estados Unidos. El castigo consiste en la remoción del cargo y la inhabilidad a futuro para ejercer cargos. Además, quienes han sido condenados por este procedimiento no pueden ser indultados. En este país el impeachmentse inscribe en el marco del checks and balances. Así, el poder conferido al legislativo busca prevenir los abusos del ejecutivo y del judicial. Sobre el particular léase: Berger, R. (1974). Impeachment: The Constitutional Problems, Cambridge: Harvard University. Gerhardt, M. J. (1996). The Federal Impeachment Process: A Constitutional and Historical Analysis, Princeton, N.J: Princeton University Press; Vergniolle de Chantal, F., (2000). L'analyse constitutionnelle de l' impeachment aux États-Unis In: Revue Française de Science Politique, 50e année,1, pp. 147-154 ; Stolz, P,. (1969), Disciplining Federal Judges: Is Impeachment Hopeless? California Law Review, 57(3), p. 659-670.

39 Las funciones de la comisión de investigación y acusación han sido previstas en la ley 5 de 1992 y la ley 273 de 1996.

40 Para más información ver: Colombia, Congreso de la República, Ley 5 de 1992, Diario Oficial n. ${ }^{\circ} 40.483$ de 18 de junio de 1992. Artículo 311. 
presidente Álvaro Uribe Vélez. La segunda alta Corte que más procesos tenía en contra de sus miembros en 2010 era el Consejo Superior de la Judicatura: 170 . Un $48 \%$ de las denuncias se dirigieron contra miembros de su Sala Disciplinaria (López Daza, 2010). Este porcentaje es un indicador del avanzado estado de descomposición que en ciertas épocas ha caracterizado a esta sala. ${ }^{41}$ Finalmente, la alta corte que menos investigaciones tiene en su contra (aproximadamente 28) es la Corte Constitucional. ${ }^{42} \mathrm{El}$ alto número de denuncias en contra de miembros de la Corte Suprema de Justicia y del Consejo Superior de la Judicatura desentona con la lentitud del trámite y la ausencia de sanciones. ${ }^{43}$

\subsection{Principales inconvenientes en la célula legislativa que investiga a los aforados}

Trabas ligadas al Procedimiento. Una de las quejas más frecuentes contra la referida Comisión es la lentitud en el trámite de las denuncias. A continuación, señalo varios hechos que pueden hacer engorroso el procedimiento. El primero es el tiempo de sesiones de la Comisión de Investigación y Acusación; debe tenerse en cuenta que esta célula legislativa labora en los mismos periodos previstos para el Congreso. ${ }^{44}$ En la práctica, esto implica que durante los recesos parlamentarios, las investigaciones contra aforados se estancan. A su vez, durante el tiempo normal de las sesiones, los miembros de la comisión de investigación y acusación pueden no tener o no estar dispuestos a dedicar todo su tiempo al tratamiento de expedientes. ${ }^{45}$ En efecto, salvo casos altamente mediatizados, la dedicación de tiem-

41 Entre los escándalos protagonizados por los miembros de esta institución en los últimos cinco años se encuentran: 'el carrusel de las pensiones', 'la falsificación de actas', 'la venta de fallos' y 'tráfico de influencias'.

42 Carlos Cortés Castillo, (8 de mayo de 2010), La Silla Vacía. Recuperado de http://www. lasillavacia.com/historia/12350.

43 Según el diario El Tiempo, "Desde 1972 (no hay contabilidad de procesos anteriores), la Comisión de Investigación y Acusación ha abierto 3.058 procesos, de los cuales archivó 1.765 y tiene vigentes 1.293 (...)" (Valero, 2012).

44 Esto significa que el primer periodo de sesiones ordinarias se extiende desde el 20 de julio hasta 16 de diciembre. Por su parte el segundo tipo de estas sesiones, se desarrolla entre el 14 de marzo y concluye el 20 de junio.

45 En 2012 se calculaba que cada miembro de la comisión debía ocuparse en promedio de 100 expedientes. 
po y esfuerzo disminuye para consagrarse a otros proyectos que pueden ser más beneficiosos frente al electorado. La escasez de tiempo fue, por ejemplo, la razón esgrimida por un congresista que ocupaba la Presidencia de la Cámara de Representantes y a su vez hacía parte de la Comisión de Investigación y Acusación. Esta dualidad de funciones lo llevó a dimitir de su cargo argumentando:46 "Mi actual condición de presidente de la Cámara, me impide dedicarle el tiempo y el esfuerzo exigidos para ser parte de la Comisión de Investigaciones".

En este orden de ideas, la falta de autonomía de la Comisión de Investigación y Acusación, también puede generar retardos en el trámite de los expedientes. Debe tenerse en cuenta que según la ley, la comisión debe apoyarse en otras autoridades tratándose de desarrollar ciertas actividades y práctica pruebas. Esto significa que el avance en el trámite de un expediente depende de la rapidez y eficacia en la gestión de organismos externos.

La forma prevista para asignar los expedientes entre los miembros de la Comisión de Investigación y Acusación es otro aspecto que traba la gestión. Según lo previsto por el reglamento del Congreso, el reparto debe hacerlo el presidente de la Comisión de Investigación y Acusación. ${ }^{47}$ En la práctica este hecho puede generar que casos sensibles sean instruidos por Congresistas afines al investigado, quienes podrían por ejemplo retardar o agilizar el trámite o incluso favorecerle a través de su decisión.

\section{Problemas con el personal que integra la Comisión de Investigación y Acusación}

La escasez de personal y la poca pericia de quienes integran la Comisión de Investigación y Acusación debilitan su gestión. Según lo previsto por la ley, la célula legislativa está compuesta por quince miembros. Nada se dice sobre la formación, experiencia o calidades que deben reunir los

46 Véase, El Presidente de la Cámara renuncia a la Comisión de Acusaciones, (12 de septiembre de 2012), El Espectador.

47 El artículo 331 de la Ley 5 de 1992, modificado por la Ley 273 de 1996 dice: "El Presidente de la Comisión de Investigación y Acusación, dentro de los dos (2) días siguientes, repartirá la denuncia o queja entre los representantes que integran la Comisión, pudiendo designar hasta tres (3) representantes investigadores para un asunto determinado. En tal caso, designará a uno de ellos coordinador. El representante investigador o representantes investigadores, dentro de los dos (2) días siguientes, citarán al denunciante o quejoso para que se ratifique bajo juramento". 
congresistas que la integran. Varios son entonces los reproches que pueden hacerse a esta célula legislativa.

El primero, es la escasez del personal que debe llevar a cabo las investigaciones. En efecto, 15 personas no son un número suficiente para conocer de numerosos y bien intrincados expedientes. A lo anterior se suma el hecho de que no existe suficiente personal que apoye técnicamente la labor. Cada miembro de la comisión posee en promedio de dos a tres asistentes. Este número de personas, puede resultar insuficiente para recibir las denuncias y realizar los trámites que se derivan de las investigaciones.

$\mathrm{El}$ segundo inconveniente, ligado a los miembros que componen la $\mathrm{Co}^{-}$ misión de Investigación y Acusación, es la ausencia de la pericia suficiente para instruir los expedientes. Según lo previsto por la ley, la Comisión de Investigación y Acusación indaga por hechos que pueden constituir faltas disciplinarias, pero también conductas tipificadas por la ley penal. En la práctica no se requiere el diploma de abogado, ni experiencia judicial de ningún tipo para conocer de las investigaciones. Este hecho puede dificultar las investigaciones que indudablemente tienen un fuerte componente legal. Por ejemplo, tratándose de la comisión de delitos, la formación jurídica o la experiencia previa en el medio judicial serían deseables. La tendencia que recientemente ha tomado fuerza en el Congreso es nombrar a personas que tengan el diploma de abogado, como mínimo. Este hecho se deduce del análisis de la actual composición de la Comisión de Investigación y Acusación. ${ }^{48}$ En conclusión, esta falta de pericia puede hacer que el trámite sea lento y la argumentación de las decisiones deficiente y altamente cuestionable.

Otro problema es el cuestionamiento ético hecho a algunos de los integrantes de la Comisión de Investigación y Acusación que han sido acusados y juzgados por la Corte Suprema de Justicia por la comisión de ilícitos. Varios son los casos sobre el particular. Por ejemplo, el de una parlamentaria que fue condenada por la Corte Suprema de Justicia por tráfico de influencias ${ }^{49}$

48 En el momento de redacción del presente texto, la comisión tiene catorce (14) miembros de los cuales ocho (8) son abogados titulados. Tres (3) de sus miembros son administradores de empresas y uno (1) es trabajador social. Sin embargo (aún en el caso de los abogados titulados), la mayoría de estos congresistas tienen una vasta experiencia en el medio político y muy escasa en el judicial.

49 Corte Suprema de Justicia, 23 de mayo de 2012, Sala de casación penal. MP Julio Enrique Socha Salamanca. 
o el de un representante a quien el Consejo de Estado retiró su investidura por violación al régimen de inhabilidades e incompatibilidades..$^{50}$

Finalmente, existe el problema del cruce de funciones de juzgamiento entre miembros de la Corte Suprema y del Congreso. En la práctica, la Corte Suprema de Justicia es la encargada de investigar y juzgar a los miembros del Congreso. Por su parte este último conoce de las denuncias contra los primeros. Este 'cruce' de funciones mella la independencia de la Comisión de Investigación y Acusación, que puede temer adelantar investigaciones contra los miembros de la Corte Suprema por temor a represalias. Sobre el particular, es muy concluyente el hecho de que en 2009 varios miembros de la comisión especularan sobre su renuncia (E1 Tiempo, 2009).

Bajo estas condiciones no puede impresionar el hecho de que muchas de las investigaciones tarden años, sean archivadas o finalicen con auto inhibitorio o preclusión. Este proceder ha dejado en la opinión pública la sensación de: 'no-justicia o manipulación de sus decisiones por los detentadores del poder político o judicial' (López Daza, 2010).

Ahora bien, los inconvenientes arriba descritos, pueden ser causas eficientes de esta gestión ineficaz. Así, presento algunas cifras sobre el número de procesos conocidos y el estado en que se encuentran en la Comisión de Investigación y Acusación. La ausencia de información en el Congreso es uno de los mayores problemas para cualquier tipo de investigación que pretenda medir los resultados de su gestión. Los datos que se analizan en este texto se extrajeron de la página web del Congreso de la República, ${ }^{51}$ específicamente de la Comisión de Investigación y Acusación, la cual presenta un reporte titulado: Procesos reales vigentes 2010-2014. Resalto que no existe información disponible en la página web del Congreso de la República anterior a este reporte. Frecuentemente la comisión aduce que la carencia de cualquier tipo de información se explica por la obligación de guardar la información del sumario. Por no hacer parte del presente estudio, los procesos adelantados contra el Presidente de la República, miembros de

50 Para más información consultar: Consejo de Estado le retira investidura al Congresista Héctor Vergara, (21 de agosto de 2012), El Tiempo.

51 Los datos se encuentran disponibles en la página web, http://www.camara.gov.co/portal2011/proyectos-vigentes-comision-investigacionconsultada el 2 de septiembre de 2013. 
la Corte Constitucional, Consejo de Estado y Fiscalía general de la nación, no serán tenidos en cuenta.

\subsection{Algunos indicadores sobre las deficiencias en la gestión}

El análisis de esta investigación está organizado como sigue. En una primera fase, se diseñó y completó la siguiente ficha en el programa Word. El objetivo fue conocer y organizar los datos pertinentes para construir este artículo, que se encontraban dispersos en un vasto archivo de la Comisión de Investigación y Acusación. En un segundo momento, los datos recolectados fueron sometidos a tratamiento estadístico, a través del programa Excel. El objetivo de esta segunda fase fue conocer exactamente la cantidad, tipo de proceso y estado del trámite. A continuación se presentan los resultados de este trabajo.

\begin{tabular}{|l|}
\hline Expediente radicado bajo el número: \\
\hline Contra: \\
\hline Delito: \\
\hline Denunciante: \\
\hline Fecha de inicio: \\
\hline Representante investigador: \\
\hline Estado actual: \\
\hline
\end{tabular}

Fuente: elaboración propia.

Las denuncias contra los magistrados de la Corte Suprema de Justicia $y$ del Consejo Superior de la Judicatura

El documento consultado de la Comisión de Investigación y Acusación reseña la existencia de 1.226 expedientes en curso, de los cuales 474 $(38,6 \%)$ corresponden a investigaciones en contra de magistrados del Consejo Superior de la Judicatura y de la Corte Suprema de Justicia. Esta última institución registra un total 250 (20,39\%) expedientes conocidos por la Comisión de Investigación y Acusación de la Cámara. Las denuncias son formuladas contra uno o varios de sus miembros, o contra la institución en general. El más antiguo de estos expedientes data del año 2002 y 
el más reciente del año 2011. En el expediente se reseñan las faltas por las que cursa la denuncia, las cuales pueden ser de tipo penal, disciplinario, incidente de desacato o por establecer. Entre los delitos denunciados se encuentran la injuria, el prevaricato, el asesoramiento ilegal y el peculado. Nada se detalla sobre las quejas disciplinarias y las llamadas 'conductas por establecer'.

De otro lado, los casos conocidos por la Comisión de Investigación y Acusación en los que están implicados miembros del Consejo Superior de la Judicatura son en total 224 (18,17\%). Los expedientes más antiguos se remontan al año 2002 y los más recientes al año 2011. Entre las denuncias de tipo penal, se señalan hechos como la injuria y el prevaricato. Tal y como ocurre en el caso de la Corte Suprema de Justicia, no se dan detalles sobre los tipos de infracción disciplinaria y las conductas 'por establecer'. La siguiente tabla muestra el número total de expedientes en contra de magistrados la Corte Suprema y el Consejo Superior de la Judicatura. Del mismo modo detalla numéricamente la cantidad de denuncias penales, quejas disciplinarias, incidentes de desacato y conductas por establecer.

Tabla 1. Tipo de denuncias en la Comisión de Investigación y Acusación de la Cámara contra miembros de la Corte Suprema de Justicia y del Consejo Superior de la Judicatura (2010-2014)

\begin{tabular}{|l|c|c|c|c|c|}
\hline \multicolumn{1}{|c|}{ Tribunal } & $\begin{array}{c}\text { Denuncia } \\
\text { penal }\end{array}$ & $\begin{array}{c}\text { Queja } \\
\text { Disciplinaria }\end{array}$ & $\begin{array}{c}\text { Incidente de } \\
\text { desacato }\end{array}$ & $\begin{array}{c}\text { Por } \\
\text { establecer }\end{array}$ & Total \\
\hline Corte suprema de Justica & 11 & 20 & 17 & 202 & 250 \\
\hline Consejo Superior de la Judicatura & 4 & 15 & 4 & 201 & 224 \\
\hline Total expedientes & 15 & 35 & 21 & 403 & 474 \\
\hline
\end{tabular}

Fuente: elaboración propia.

La figura 1 muestra el porcentaje de denuncias contra magistrados de la Corte Suprema de Justicia y del Consejo Superior de la Judicatura. Tal y como se observa, un $85 \%$ de los hechos conocidos por la Comisión de Investigación y Acusación de la Cámara se encuentran en la categoría 'por establecer'. Esto significa que aún no existe certeza sobre si se trata de hechos que constituyen faltas penales, disciplinarias o simples incidentes de desacato. Esta enorme cantidad de expedientes en la categoría por establecer 'es un indicador de la lentitud de la gestión de la comisión. 


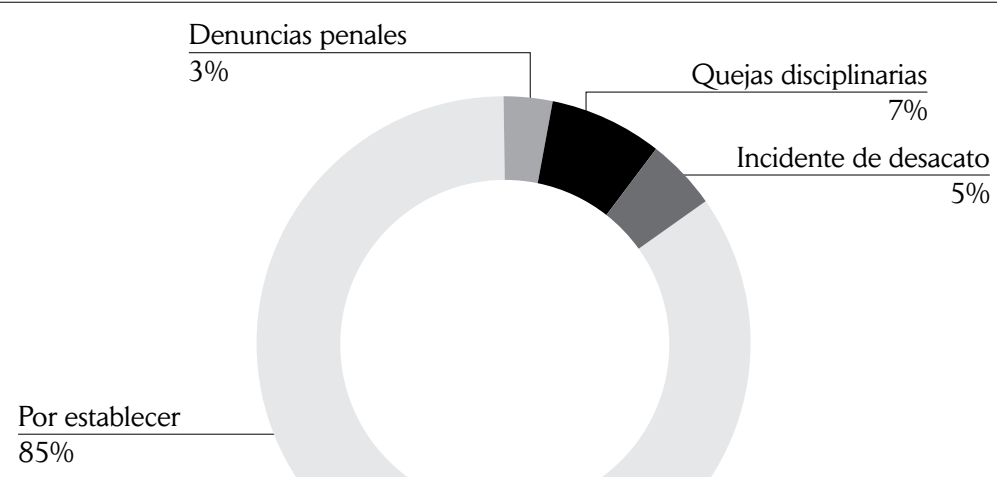

Figura 1. Tipo de falta denunciada Corte Suprema de Justicia y Consejo Superior de la Judicatura (2002-2014)

Fuente: elaboración propia.

Estado del trámite de los expedientes en la comisión de Investigación y Acusación de la Cámara. Frecuentemente se aduce que los expedientes que son conocidos por la Comisión de Investigación y Acusación, al entrar en esta instancia: "duermen el sueño de los justos" (Castillo, 2010). Esta afirmación se relaciona con la parálisis de en las investigaciones, hecho que se denuncia con frecuencia. La siguiente tabla muestra el número de expedientes que se encuentran en 'preliminares'. En la Corte Suprema de Justicia son 239 los procesos que se encuentran en preliminares, con archivo y uno pendiente de recurso. El panorama en el Consejo Superior de la Judicatura no es más alentador: 215 procesos se encuentran en preliminares, cuatro han sido archivados y diez se encuentran en la categoría pendiente de recurso.

Tabla 2. Estado del trámite de los expedientes (2010-2014)

\begin{tabular}{|l|c|c|c|c|}
\hline \multicolumn{1}{|c|}{ Tribunal } & Preliminares & Archivo & Pendiente de recurso & Total \\
\hline Corte Suprema de Justicia & 239 & 5 & 1 & 245 \\
\hline Consejo Superior de la Judicatura & 215 & 4 & 10 & 229 \\
\hline Total & 454 & 9 & 11 & 474 \\
\hline
\end{tabular}

Fuente: elaboración propia. 
Finalmente, el siguiente gráfico ilustra cómo $95,78 \%$ de los procesos que se adelantan en la Comisión de Investigación y Acusación de la Cámara de Representantes contra miembros del Consejo Superior de la Judicatura y de la Corte Suprema de Justicia se encuentran en preliminares. Este alto porcentaje contrasta con el escaso número de expedientes archivados: 1,90\%.

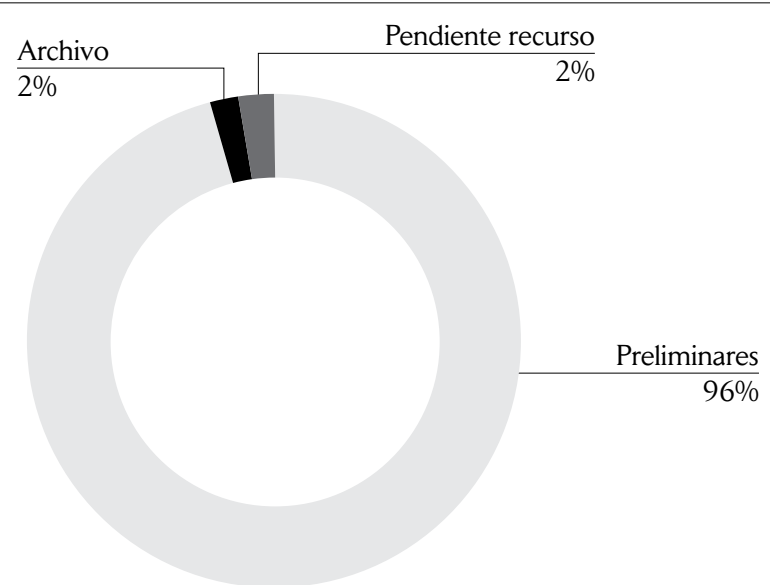

Figura 2. Estado del trámite de los expedientes (2010-2014)

Fuente: elaboración propia.

\section{Conclusiones}

Varias conclusiones pueden extraerse a propósito de la rendición de cuentas de los magistrados de la Corte Suprema y del Consejo Superior de la Judicatura en Colombia. La primera es que existe un amplio conjunto de normas constitucionales y legales, que buscan que los jueces respondan por sus acciones y por sus omisiones. Así, fruto de una amalgama de elementos que se aproximan a las dos grandes tradiciones jurídicas, se han previsto algunas medidas que buscan mejorar la gestión de los tribunales. Estas acciones, puestas en obra por la sala administrativa del Consejo Superior de la Judicatura, pueden ser leídas como desarrollos incipientes de judicial accountability. También se han implementado mecanismos que buscan asegurar la responsabilidad de los jueces a través de controles de tipo disciplinario y penal. En estos casos, el común denominador es que los altos 
jueces gozan de una especie de inmunidad que hace que el control sobre sus acciones sea ejercido por la comisión al seno del Congreso colombiano. Pese a la existencia de estos diseños institucionales que buscan compensar las garantías de independencia con la exigencia de responsabilidad, en la práctica estos arreglos gozan de una débil eficacia.

La segunda es que una de las principales fracturas al sistema de responsabilidad de jueces es el inadecuado funcionamiento de la Comisión de Investigación y Acusación de la Cámara de Representantes. La falta de una gestión óptima de la Comisión hace que en la práctica los altos jueces en Colombia den pocas cuentas sobre sus acciones y por ende gocen de una legitimidad atenuada. No puede pasarse por alto que la falta de legitimidad de la sala disciplinaria del Consejo Superior de la Judicatura es especialmente grave. Se debe tener en cuenta que esta instancia es el juez de los jueces, por lo que su irresponsabilidad puede ser un incentivo poderoso para la comisión de acciones indebidas en niveles jerárquicos inferiores.

La tercera es que empiezan a emerger mecanismos que buscan asegurar la accountabiliy horizontal, ante las falencias anotadas en los mecanismos de control formal. Se trata de pronunciamientos a través de los cuales la Corte Constitucional y el Consejo de Estado han sentado bases claras sobre algunos principios que deben orientar la acción de sus colegas y en general la administración de justicia. En este mismo escenario han aparecido formas de control informal que se originan en medios de comunicación y organizaciones no gubernamentales. ${ }^{52}$ Sobre el particular, es especialmente ilustrativa una situación. Los hechos sucedieron cuando un magistrado de la sala disciplinaria se vio envuelto en un escándalo por supuesta corrupción en el mes de noviembre de 2013. Según revelaciones hechas por un importante medio de comunicación, el magistrado habría recibido importantes sumas de dinero para que los llamados procesos por falsos positivos fueran conocidos por la justicia penal militar. ${ }^{53}$ Las denuncias y la presión ejercida por los medios de comunicación condujeron a que el magistrado renunciara a su cargo. Este es un hecho importante, en la medida en la que

52 Se trata de accountability social.

53 Sobre el particular léase: Las grabaciones que incomodan al magistrado Villarraga (27 de octubre de 2013), El espectador. El otro escándalo del magistrado Villarraga, (28 de Octubre de 2013), Semana. 
en otros escándalos protagonizados por miembros de la sala disciplinaria del Consejo, los magistrados han optado por retirarse temporalmente de su cargo, luego de lo cual regresan a sus funciones y terminan sus periodos de ley sin que sus conductas sean reprendidas de manera alguna.

Frente a este panorama, es necesario afinar el diseño institucional previsto para la investigación y juzgamiento de faltas de los altos jueces. Sin embargo, estas acciones pueden ser inútiles si no son acompañadas de medidas que garanticen no solo el ingreso de los mejores a los cuerpos judiciales, sino la interiorización de un cuerpo deontológico que enmarque sus acciones dentro y fuera de los estrados.

\section{Referencias}

A indagatoria jueces de 109 representantes, (20 de octubre de 1998). El Tiempo. Badel Rueda, M. (2008). La corrupción judicial en Colombia. Una aproximación al mapa de riesgos, Bogotá: Corporación excelencia por la Justicia y Corporación Transparencia por Colombia Usaid.

Berger, R. (1974). Impeachment: The Constitutional Problems, Cambridge: Harvard University.

Bericat, E. (1998). La integración de los métodos cuantitativo y cualitativo en la investigación social: Significado y medida, Barcelona: Ariel.

Cadiet, L. (2011). Le nouveau management de la justice et l'indépendance des juges, Paris: Dalloz.

Commaret, D. (2000). Les responsabilités déontologiques des magistrats á la lumière de la jurisprudence du Conseil Supérieur de la magistrature, En Association française pour l'histoire de la justice, (Ed. scientifique). Juger les Juges. Du Moyen Age au Conseil Supérieur de la Magistrature, Paris: La documentation Française.

Canivet, G., Andenæs, M. T., \& Fairgrieve, D. (eds.). (2006). Independence, Accountability, and the Judiciary, London: British Institute of International and Comparative Law.

Canivet, G., \& Joly-Hurard, J. (2006). La responsabilité des juges, ici et ailleurs. Revue internationale de droit comparé, 58(4), pp. 1049-1093.

Canivet, G., E Joly-Hurard J. (2009). La déontologie du magistrat, París: Dalloz.

Canivet, G. (2003). La responsabilité des juges: approche comparative. En M. Deguergue, \& P. Ardant. Justice et responsabilité de l'état, Paris: Presses Universitaires de France. 
Canivet, G. (2008). La responsabilité des juges: approche comparative $n$ La responsabilité des magistrats: actes du [6eme] colloque organisé à Limoges le 18 novembre 2005. S. Gaboriau, H. Pauliat, (eds.) Presses Univ. Limoges.

Coffey, A., \& Atkinson, P. (2005). Encontrar el sentido a los datos cualitativos: estrategias complementarias de investigación, Alicante: Universidad de Alicante.

Colombia, Congreso de la República de Colombia. Proyectos vigentes comisión de Investigación y Acusación. Disponible en http://www.camara.gov.co/portal2011/proyectos-vigentes-comision-investigacion.

Colombia, Consejo de Estado, 16 de abril de 2012, n. ${ }^{\circ} 1100103060002012-0015-$ 00, Sala de consulta y servicio civil, CP Augusto Hernández Becerra.

Colombia, Corte Constitucional, 18 de septiembre de 2008, T-910 de 2008, M.P. Manuel José Cepeda.

Colombia, Corte Suprema de Justicia, (2010). Procesos contra aforados constitucionales - Parapolítica. Compilación de autos y sentencias de la Sala de Casación Penal de la Corte Suprema de Justicia, Bogotá: Ed. ASDI-Centro Internacional para la Justicia Transicional.

Colombia, Corte Suprema de Justicia, 18 de febrero de 1987, Sala de casación penal, M.P. Guillermo Dávila Muñoz.

Colombia, Corte Suprema de Justicia, 23 de mayo de 2012, Sala de casación penal. M.P. Julio Enrique Socha Salamanca.

Colombia, Corte Constitucional, 22 de agosto de 1996, C-385 de 1996, M.P. Antonio Barrera Carbonell.

Colombia, Sala Disciplinaria del Consejo Superior de la Judicatura, 29 de Marzo de 2012, Radicado 110010200020120024300, M. P. Pedro Nel Escorcia Castillo.

Colombia, Congreso de la República, Acto legislativo n. ${ }^{\circ} 1$ de 1968, Diario Oficial n. ${ }^{\circ} 32.673$ de 17 de Diciembre de 1968.

Colombia, Congreso de la República, Decreto n. ${ }^{\circ}$ 1698, julio 16 de 1964.

Colombia, Congreso de la República, Ley 734 de 2002, Diario Oficial n. ${ }^{\circ} 44.708$ de 13 de febrero de 2002.

Colombia, Congreso de la República, Ley 270 de 1996, Diario Oficial 42.745 del 15 de marzo de 1996, Artículo 151.

Contini, F., \& Mohr, R. (2007). Reconciling independence and accountability in judicial systems. Utrecht Law Review 3, p. 26.

Cortés Castillo, C. (08 de mayo de 2010). Las investigaciones en la Comisión de Acusaciones: durmiendo el sueño de los justos. La Silla Vacía. Recuperdado de http://www.lasillavacia.com/historia/12350

De Colombia, C. P. (1991). Bogotá. Recuperado de http://wsp.presidencia.gov. co/Normativa/Documents/Constitucion-Politica-Colombia.pdf 
Domínguez, H. B. (1981). Móviles ocultos de una justicia, Bogotá: Canal RamírezAntana.

Durand, Y. (2003). La responsabilité de la justice et des juges en Espagne. En

Deguergue, M., \& Ardant, P, Justice et responsabilité de l'état. p.90, Paris: Presses Universitaires de France.

El otro escándalo del magistrado Villarraga (28 de Octubre de 2013). Semana.

Francia, Conseil Supérieur de la Magistrature. Rapport d'activité 2002-2003. Recuperado de http://www.conseil-superieurmagistrature.fr/sites/all/themes/ csm/rapports/rapport2003.pdf

Frydman, B., E Jeuland E. (2011). Le nouveau management de la justice et l'indépendance des juges. Paris: Dalloz.

Garoupa, N., E Ginsburg, T. (2009). Guarding the guardians: Judicial councils and judicial independence. American Journal of Comparative Law, 57(1), pp. 103-134.

García Villegas, M., \& Revelo Rebolledo, J. (2010). Estado Alterado Clientelismo, mafias y debilidad institucional en Colombia, Bogotá: Dejusticia.

Gerhardt, M. J. (1996). The Federal Impeachment Process: A Constitutional and Historical Analysis Princeton, N.J: Princeton University Press

Gur-Arie, M., E Wheeler, R. (2002). La independencia judicial en los Estados Unidos: temas de actualidad e información relevante sobre antecedentes. USAID, Pautas para promover la independencia y la imparcialidad judicial, Washington DC: USAID.

Guevara Rivera, C. (2007). Análisis de la influencia del constitucionalismo francés en la Constitución Politica de 1991. (Tesis de Maestría, Universidad Nacional de Colombia, Bogotá, Colombia).

Las grabaciones que incomodan al magistrado Villarraga. (27 de octubre de 2013). El Espectador.

López Daza, G. (2010). El control político en Colombia: El papel de la Comisión de Investigación y Acusaciones de la Cámara, Neiva: Universidad Surcolombiana.

López Hernández, C., E Ávila Martínez, A. (2010). Y refundaron La Patria: de cómo mafiosos y politicos reconfiguraron el Estado colombiano, Bogotá: Debate.

López, D. (2004). Teoría impura del derecho, Bogotá: Legis.

Magistrados se rebelan contra Pablo Ardila, (22 de Octubre de 1998). El Tiempo. Osorio Chacón, Á. (2003). Responsabilidad de los altos funcionarios del Estado, Juicios ante el congreso, Bogotá: Ediciones Nueva Jurídica.

Pérez Perdomo, R. (2001). Independencia y responsabilidad de los jueces. Gestión $y$ análisis de políticas públicas, (20), pp. 97-102. 
Peri, A. (2012). Judicial Independence vs Judicial Accountability, Judicial Selection models for constitutional courts. A comparative Analysis. In Comparative Law Review, 3 (1), pp. 1-30.

Presidencia de la República de Colombia. Comunicado oficial de la Presidencia de la Republica $n .{ }^{\circ} 68$ del 17 de Enero. Disponible en http://web.presidencia.gov.co/ comunicados/2008/enero/64.html.

Revelo Rebolledo, J. (2009). El Consejo Superior de la Judicatura entre eliminación y cooptación. En M. García Villegas \& J. Revelo Rebolledo (eds.). Mayorías sin democracia: desequilibrio de poderes y Estado de derecho en Colombia 2002-2009, Bogotá: Dejusticia.

Renoux, T. (2000). Les Conseils Supérieurs De La Magistrature En Europe: Actes De La Table Ronde Internationale Du 14 Septembre 1998, Paris: La Documentation française.

Revista del Tribunal Disciplinario, Estudios y documentos, Año 5- volumen II- último número. Enero 1986 a diciembre de 1991.

Ríos Delgado, S., \& Suárez Sandoval, Y. (2011). La sala disciplinaria del Consejo Superior de la Judicatura: entre la independencia judicial y la captura política. (Tesis de pregrado, Universidad Pedagógica y Tecnológica de Colombia, Tunja, Colombia).

Schauffler, R. (2007). Judicial Accountability in the US State Courts: Measuring Court, Performance. Recuperado de: http://www.utrechtlawreview.org/index.php/ulr/ article/view/URN\%3ANBN\%3ANL\%3AUI\%3A10-1-101059/40

Schedler, A. (1999). Conceptualizing accountability. En A. Schdeler, L. Diamondy E M. F. Plattner (eds.). The self-restraining State: power and accountability in new Democracies (pp.13-28). Boulder, Co: Lynne Rienner.

Stolz, P. (1969). Disciplining Federal Judges: Is Impeachment Hopeless? California Law Review, 57(3), pp. 659-670.

Universidad Externado de Colombia. Instituto de Ciencias Penales, \& Criminológicas. Curso de Maestría. (1994). Corrupción administrativa y delincuencia judicial. Universidad Externado de Colombia.

Valero, D. (12 de febrero de 2012). Un tribunal de 40 años y una condena. El Tiempo.

Vergniolle de Chantal, F. (2000). L'analyse constitutionnelle de 1' impeachment aux États-Unis. Revue Française de Science Politique, 50(1), pp. 147-154. 